\title{
MUJERES INDÍGENAS ROMIPEN EL SILENCIO Y EXIGEN JUSTICIA TRIBUNAL DE CONCIENCIA SOBRE VIOLENCIA DE GÉNERO EN MÉXICO
}

\author{
INDIGENOUS WOMEN BREAK THE SILENCE AND DEMAND JUSTICE \\ COURT OF CONSCIENCE ON GENDER VIOLENCE IN MEXICO \\ MULHERES INDÍGENAS QUEBRAM O SILÊNCIO E EXIGEM JUSTIÇA \\ TRIBUNAL DE CONSCIÊNCIA SOBRE VIOLÊNCIA DE GÊNERO NO \\ MÉXICO
}

Maria Teresa Sierra

Profesora-Investigadora Titular Centro de Investigaciones y Estudios Superiores en Antropología Social mtsierrac@hotmail.com México

\section{Dolores Figueroa Romero}

Doctora en Sociología Catedrática CONACYT adscrita al Centro de Investigaciones y Estudios Superiores en Antropología Social dolores.figueroa@ciesas.edu.mx

México

\section{Resumen}

Este artículo ofrece una lectura antropológica de la falta de acceso a la justicia que viven las mujeres indígenas en Guerrero como parte del cúmulo de opresiones que afectan sus vidas y la de sus comunidades. A partir del seguimiento de Tribunales de Conciencia nos interesa visibilizar los sentidos sociales de agravio y daño que revela el testimonio de mujeres víctimas de violencia, así como las posibilidades que ofrece el acompañamiento legal de defensoras de derechos humanos a sus demandas de resarcimiento y justicia, inclusive más allá de los espacios judiciales. Asimismo, 
nos interesa poner en relevancia los alcances y límites de los Tribunales de Conciencia para avanzar posible reparaciones culturalmente adecuadas y sensibles a sus contextos.

Palabras clave: Violencia estructural, feminicidio, Montaña de Guerrero, mujeres indígenas, justicia de género, derechos humanos, Tribunales de Conciencia

\begin{abstract}
This paper conveys an anthropological analysis of the lack of access to justice experienced by indigenous women in Guerrero and which reveals the accumulation of oppressions that affect their lives and that of their communities. From the follow-up of Courts of Conscience, we are interested in making visible the social senses of grievance and damage revealed by the testimony of women and the possibilities that the legal accompaniment of human rights defenders can give to demands for compensation, exceeding even the justice of the State. Likewise, we are interested in highlighting the scope and limits of the Courts of Conscience to advance possible reparations culturally appropriate and sensitive to their contexts.
\end{abstract}

Keywords: Structural violence, feminicide, Mountain region of Guerrero, indigenous women, gender justice, human rights, Courts of Conscience

\title{
Resumo
}

Este artigo oferece uma leitura antropológica da falta de acesso à la justiça que vivem as mulheres indígenas em Guerrero e que revela o cúmulo de opressões que afetam suas vidas e as de suas comunidades. A partir do monitoreamento dos Tribunais de Consciência, nos interessa tornar visíveis os significados sociais das denúncias e danos revelados pelo testemunho de mulheres vítimas de violência de gênero e as possibilidades oferecidas por mulheres defensoras dos direitos humanos às demandas de reparação que vão além do sistema de justiça do Estado. Da mesma forma, interessa-nos destacar o alcance e os limites dos Tribunais de Consciência para fazer avançar possíveis reparações culturalmente adequadas e sensíveis a contextos.

Palavras-chave: Violência estrutural, feminicídio, região serrana de Guerrero, mulheres indígenas, justiça de gênero, direitos humanos, Tribunais de Consciência 
Este Tribunal por los derechos de las mujeres es un esfuerzo más para colocar en la opinión pública el grave problema de los feminicidios en Guerrero, y mostrar que en medio de estas atrocidades existen rostros luminosos que luchan por la justicia, que han honrado a las mujeres que han sido silenciadas y que no han encontrado reposo ante falta de justicia"

(Abel Barrera, Tribunal de Conciencia, 6 de marzo 2018, Chilpancingo, Gro).

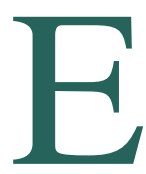

16 de marzo del 2018 el Centro de Derechos Humanos de la Montaña Tlachinollan organizó el Tribunal de Conciencia (TC): "Los Rostros Luminosos de la Justicia" en la sede del poder judicial del estado de Guerrero, en la ciudad de Chilpancingo. Para este Tribunal fueron convocadas gente de la sociedad civil, observadores de derechos humanos, abogadas, académicas aliadas, especialistas en defensoría y funcionarios del poder judicial para escuchar de viva voz el relato de las violencias y atropellos cometidos contra cuatro mujeres indígenas de la Montaña de Guerrero. El propósito de este evento fue doble, por un lado, se buscaba sensibilizar al poder judicial estatal sobre la cadena de impunidad y obstáculos sistemáticos que enfrentan las mujeres para acceder a la justicia, y por otro, visibilizar los agravios y

\footnotetext{
${ }^{1}$ Los casos legales incluidos en el texto, los testimonios, así como la información contextual por parte de la defensoría de Tlachinollan proviene de nuestra asistencia a los tres Tribunales de Conciencia que se han realizado en la ciudad de Chilpancingo desde el 2018. El ensayo incluye conversatorios con la abogada Neil Arias
}

los reclamos de mujeres víctimas y así llegar a una comunidad ampliada que permita acuerpar a las mujeres afectadas y sus familias. Este fue el primero de tres Tribunales de Conciencia que ha organizado Tlachinollan en el marco del Día Internacional de la Mujer para apuntalar la exigencia social y política de hacer justicia a las mujeres indígenas que viven violencia.

Con base en casos que se presentaron en los distintos Tribunales de Conciencia - los que su defensoría ha seguido curso por varios años- $^{1}$ queremos hacer una lectura antropológica de la problemática de la violencia extrema que viven las mujeres indígenas en Guerrero, la racialización y excusión que enfrentan en la búsqueda de justicia y lo que revela del cúmulo de opresiones que afectan sus vidas y la de sus comunidades. Nos interesa visibilizar los sentidos sociales de agravio y daño que involucra el testimonio de las mujeres y las posibilidades de resarcimiento que rebasan la justicia del Estado y que requieren de otros canales como la mediación e involucramiento de actores comprometidos con la defensa, el registro y el acompañamiento de las víctimasdemandantes. Asimismo, ponemos en relevancia los alcances y límites de los

Virginio, responsable del área jurídica de Tlachinollan, que se realizaron en la ciudad de Chilpancingo y en las oficinas de Tlachinollan, en la ciudad de Tlapa. Los nombres de las personas que ofrecen su testimonio han sido cambiados para proteger su identidad. 
Tribunales de Conciencia para la exigencia de justicia hacia mujeres indígenas y para una posible reparación culturalmente adecuada y sensible a sus contextos. Por ello nos preguntamos: ¿hasta qué punto el recurrir a la performatividad pública de los agravios de mujeres -silenciadas por el racismo y el clasismo estructural- puede fortalecer su demanda de justicia? y ¿cómo el ejercicio performativo de los tribunales de conciencia es adaptado por las abogadas de Tlachinollan en una nueva faceta de defensoría que tiene que ver expresamente con los derechos humanos de las mujeres y las injusticias de género? A partir de la incorporación de la violencia de género en la defensoría del Centro de Derechos Humanos Tlachinollan, este ensayo argumenta que el ejercicio de documentación y difusión testimonial de mujeres indígenas tiene claros efectos políticos y sociales como es la politización de la violencia doméstica y una comprensión más integral de las conexiones entre distintas escalas y actores institucionales y judiciales que les impiden el acceso a la justicia.

Tlachinollan desde hace relativamente poco tiempo (2018) ha inaugurado esta nueva veta de trabajo de defensoría, pues la violencia de género no era una área de trabajo abordada por

\footnotetext{
2 Agradecemos los comentarios críticos y reflexivos de Rachel Sieder sobre el expertise jurídico-legal de los defensores de derechos humanos de pueblos indígenas, que recién ha sido trastocado por la necesidad de
}

organizaciones defensoras de derechos humanos tradicionales. La defensoría de los derechos humanos en América Latina se ha centrado primordialmente en la violencia estatal y la incorporación de perspectivas de análisis legal feminista ha sido tardía (JARAMILLO SIERRA, 2020). Centros de derechos humanos como Tlachinollan surgieron inspirados por la necesidad imperiosa de visibilizar la violencia -estatal y no estatal- contra los pueblos indígenas (ESTRADA, 2009), y comúnmente no atendían problemáticas de violencia sexual y de género. Estas problemáticas era el campo de defensoría de organizaciones feministas urbanas. A ello se suma el hecho de que los defensores de derechos humanos se especializan en derecho constitucional y penal, y no de familia y derechos de mujeres. ${ }^{2}$

Sin embargo, la experiencia de Tlachinollan en los últimos años muestra que las organizaciones de derechos humanos transmutaron su labor hacia los focos de atención que la población les demanda. Esto justo ha cambiado por la presión de adoptar un enfoque feminista culturalmente sensible y responsivo a las violaciones graves que han vivido mujeres indígenas por parte del ejército y de grupos armados en el contexto de la guerra contra el narcotráfico y de la

responder y observar la interseccionalidad de las violencias que afecta a mujeres indígenas en particular. 
llamada guerra sucia en Guerrero (HERNÁNDEZ CASTILLO, 2016; ESTRADA 2014). El Centro de Derechos Humanos de la Montaña, Tlachinollan, está ubicado en la ciudad de Tlapa, al centro de la región de la Montaña, y a sus oficinas llegan cotidianamente familias afectadas por distintas violencias. Una parte importante de las personas indígenas que llegan a sus oficinas son mujeres, acompañadas de sus hijos o familiares. El reclamo de atención a sus casos hace eco de la situación de precariedad violencia que atraviesa la región en su conjunto, pero desde la particularidad de la experiencia femenina.

Un importante antecedente que ayuda a contextualizar el trabajo de Tlachinollan en temas de violencia de género contra mujeres indígenas es la experiencia en Centroamérica de Tribunales de Conciencia. Los tribunales realizados en el contexto de la post guerra fría en Centroamérica han mostrado la intrínseca conexión que hay entre la violencia estatal y macro-estructural con formas previas de discriminación racista $y$ de género que emergen en momentos de estrés social y bélico contra mujeres indígenas. Este tipo de tribunales y de formas públicas testimoniales de violaciones a derechos humanos de mujeres revelan la importancia de dar una

\footnotetext{
${ }^{3}$ Retomamos el trabajo teórico-analítico de Mariana Mora (2017) sobre la naturalización de nociones derogatorias y discriminatorias de la población indígena habitante de la Montaña de Guerrero. La mirada deshumanizante y despectiva hacia los indígenas y sus territorios tiene
}

mirada interseccional a la violencia política constituida desde la inequidad de los regímenes de género (CROSBY \& LYKES 2011, MACLEOD 2020; FIGUEROA Y BARBEYTO, 2019).

Para desarrollar nuestro argumento estructuramos el texto en cuatro partes: en la primera presentamos el marco analítico para comprender el entrecruce entre múltiples violencias y acceso a la justicia para las mujeres indígenas y el papel de los Tribunales de Conciencia como una herramienta para denunciar la impunidad y visibilizar la voz de las víctimas. En la segunda parte nos referimos al contexto estructural de las violencias en Guerrero y especialmente en la región de la Montaña Alta, sede de Tlapa de Comonfort, para comprender los asuntos judiciales que involucran a las mujeres indígenas y situar las geografías racializadas que afectan a la población campesina y rural indígena (MORA, 2017); ${ }^{3}$ en la tercera parte nos referimos a los Tribunales de Conciencia que Tlachinollan ha implementado en la ciudad de Chilpancingo destacando su dimensión ritual y performativa para mostrar los patrones de violencia de género, violencia institucional y racismo judicial que permean los casos. Por último, en la cuarta parte a partir de dos testimonios analizamos la

efectos racializantes sobre geografías específicas, justificando la aplicación de políticas y mecanismos de disciplinamiento que violentan a la población de variadas maneras (2017:71). 
dimensión de agravio y daño que traducen los casos y los efectos para las víctimas- directas e indirectas - de romper el silencio. Al poner en el centro el testimonio, el TC permite visualizar la tensión entre la racionalidad jurídica con la que la defensa construye el caso en el proceso judicial y la racionalidad cultural que emerge en la narrativa oral de la víctima lo que potencia el efecto simbólico de la denuncia y la exigencia de justicia. Esto es lo particular de los Tribunales de Conciencia -que ponen en relevancia la defensoría de derechos humanos de las mujeres- con los que se busca ejercer presión sobre los actores institucionales y judiciales, además de llegar a un público amplio (MACLEOD 2017). ${ }^{4}$

\section{Violencias múltiples y exigencia de justicia en los testimonios de mujeres indígenas.}

“...fui a preguntar a la licenciada (MP) a donde hice la denuncia y dijo: no pues ahora sí puedes denunciar, porque tu pareja ya te denunció. Pero pues, yo le dije que yo había ido primero (a poner la denuncia) ... y dice: "pues es que eso me dijo él (su esposo), que no iba hacer una denuncia en tu contra, pero pues ahora ya la puso y entonces ahora tú también la tienes que hacer". Y fue cuando la licenciada me dijo que yo era la culpable, o sea que era mayor que él

\footnotetext{
${ }^{4}$ Agradecemos la generosidad de Morna Macleod de compartirnos bibliografía relevante sobre el tema de los Tribunales de Conciencia y el papel del testimonio especialmente en temas de violencia de género, como se muestra a lo largo de este trabajo.
}

y porque era gorda, eso fue una discriminación en mi contra, por ser pobre o no sé, no me hizo justicia y pues lo que pido ahora es que cambien las cosas, que escuchen a las mujeres, lo que pido es justicia" ${ }^{5}$

Las palabras de María (anónimo), mujer me'phaa, víctima de violencia sexual e institucional, son un claro ejemplo de cómo distintas violencias se ensañan en la vida de mujeres indígenas incrementando su vulnerabilidad; no sólo viven bajo la amenaza de violencias extremas que ponen en riesgo sus vidas, por parte de perpetradores que en ocasiones son sus propios esposos, sino también sufren los efectos de la discriminación institucional a lo que se agrega la discriminación étnica y de género.

Estos son los casos que suelen llevar las defensoras de Tachinollan ante las autoridades judiciales y ante la denegación de justicia y oídos sordos han recurrido a alternativas extrajudiciales, como son los Tribunales de Conciencia, con el fin de denunciar la impunidad. En lo siguiente destacamos líneas analíticas que nos ayudan a comprender las formas de las violencias que viven las mujeres indígenas y el papel del testimonio en los TC. Dichos testimonios corresponden a voces

\footnotetext{
5 Testimonio de María (anónimo) víctima de violencia sexual que denuncia denegación de justicia y violencia institucional por parte de la Agencia Especializada en Delitos Sexuales de Tlapa (Tribunal de Conciencia TLACHINOLLAN, 6 de marzo de 2018)
} 
históricamente silenciadas que encuentran en estas audiencias públicas la posibilidad de hablar sobre los daños e injusticias vividas en su propia lengua y desde lo que ellas consideran relevante; es decir, desde sus visiones del mundo y sus lógicas culturales. Los casos que analizamos más adelante revelan el entrecruce de múltiples violencias encarnadas en el cuerpo de mujeres indígenas que traducen historias de exclusión y racismo, imbricadas con violencias patriarcales, en contextos comunitarios e institucionales. Tales violencias estructurales son claves para comprender las tramas cotidianas de la vida de las mujeres indígenas y de sus familias, y también para situar el trabajo comprometido de defensoras de derechos humanos que no cejan en generar alternativas para disputar la justicia.

Desde una visión antropológica la violencia es un fenómeno sociocultural que tiene una dimensión histórica, relacional y reproductiva de sí misma; tal es lo que plantean varios autores como Nancy Scheper-Hughes y Phillipe Bourgois (2010), Veena Das (2008) y Kymberley Teidon (2012), quienes desde la etnografía analizan la dimensión subjetiva y estructural del fenómeno develando su complejidad. El acercamiento de estas autoras escapa a explicaciones naturalizadas que relacionan la violencia ligada intrínsecamente al atraso social, a la pobreza económica y la diferencia étnicoracial. Estas naturalizaciones son funcionales a la descalificación de las sociedades indígenas por encima de la necesidad de explorar la correlación entre las estructuras de desigualdad socioeconómica y política de nuestras sociedades, y las tramas sociales $\mathrm{y}$ culturales que producen las violencias.

La violencia estructural como es la pobreza material y las diversas formas de marginación social y política engendran violencia, unas de largo aliento y otras que tienen una ocurrencia cotidiana. En el caso de comunidades indígenas de la Montaña de Guerrero, dichas violencias se engarzan al legado histórico del racismo que junto con el despojo y la migración han estructurado la vida de dichas comunidades produciendo una condición de vulnerabilidad continua que se expresa tanto en el espacio público y productivo como en el doméstico.

Las violencias son multiformes se expanden por varios territorios y en distintas esferas de la vida social produciendo nuevas geografías de desigualdad; estos contextos de violencia estructural y las limitadas condiciones para la reproducción social incrementan los conflictos en el espacio doméstico poniendo en riesgo a mujeres y a niños que se ven atrapados en círculos de violencia. Corresponden efectivamente a un 
"continuum" de violencias, siguiendo a Schepher-Huges y Bourgois (2010), que se intersectan en contextos específicos cobrando dimensiones particulares en la vida de las mujeres indígenas; por ello un acto de violencia extrema - como lo es el feminicidio -suele ser el resultado de violencias cotidianas acumuladas que involucran distintos agravios de carácter psicológico, físico, económico y sexual que en determinados momentos escalan y pueden provocar el asesinato de la persona. Para comprender estas violencias hay que situar los contextos y los actores que la provocan en el marco de estructuras patriarcales, así como las alternativas a disposición de las mujeres y sus familias para enfrentarlas.

Estudios previos han mostrado como juega la pobreza y la vulnerabilidad en la división de trabajo en las comunidades indígenas, y muy especialmente en la Montaña de Guerrero, según veremos más adelante. ${ }^{6}$ Los casos ventilados en los Tribunales de Conciencia organizados por Tlachinollan, dan cuenta del escalamiento de la violencia doméstica que puede llevar hasta la agresión y la muerte física de las mujeres.

\footnotetext{
${ }^{6}$ Guerrero es el tercer estado en la república con mayores niveles de marginación, junto con Chiapas y Oaxaca. Según el informe de evaluación de la política social del CONEVAL (2018) el 64.5 por ciento de su población sufre de condiciones de pobreza (pp. 25). A nivel municipal un poco menos del $50 \%$ de los 81 municipios tienen niveles altos o muy altos de nivel marginación social, lo que resulta en una marcada desigualdad en relación con las poblaciones mestizas (CONEVAL, 2014). La Montaña, que es la región donde vive la mayoría de la población indígena, las condiciones de
}

Es así que la violencia íntima es reflejo de un conjunto de factores que la activan, como puede ser el estrés social, el cuestionamiento al rol de proveedor de la autoridad masculina, y en general la precariedad de la vida y la disputa por bienes escasos que prevalece en la región, entre otros.

\section{Tribunales de Conciencia}

Desde fines de los años sesentas del siglo pasado los Tribunales de Conciencia adquirieron una importante notoriedad para visibilizar los crímenes de lesa humanidad cometidos de forma atroz por los gobiernos en diferentes partes del mundo. El Primer Tribunal de Conciencia, el Tribunal Internacional contra los Crímenes de Guerra en Vietnam, el llamado Tribunal Russell (1967), juzgó al gobierno norteamericano por su intervención militar y el genocidio en ese país; posteriormente otros Tribunales Éticos han sido fundamentales para develar las graves violaciones a los derechos humanos, la impunidad y la violencia involucradas en las guerras hacia enemigos externos e internos. ${ }^{7}$

marginación social, económica y política son mayores. De los 19 municipios de La Montaña, 14 están catalogados como de alto grado de marginación. Las condiciones de pobreza son multifactoriales, incluyen una falta sustancial de inversión pública en los servicios sociales estatales y conlleva a una falta de acceso adecuado a los servicios de salud y educación (Programa Regional de la Montaña, 2016-2021).

7 Para una revisión sobre los Tribunales de Conciencia y el uso del testimonio ver Macleod (2020, 2017); para el 
Desde hace dos décadas, en el presente siglo, llaman la atención un número relevante de Tribunales de Conciencia dirigidos específicamente a denunciar la violencia sexual como arma de guerra y los efectos de las múltiples violencias sobre las mujeres. En especial destacamos los Tribunales que han tenido lugar en los últimos años en Centroamérica para denunciar el conflicto armado interno y los crímenes sexuales hacia las mujeres: tal ha sido el caso del Tribunal en Honduras en contra de mujeres lenkas agredidas sexualmente ${ }^{8}$ y el Tribunal en contra de la violencia sexual en Colombia en el contexto del conflicto armado interno; ${ }^{9} \mathrm{y}$ muy especialmente el Tribunal de Conciencia "Ni Olvido ni Silencio" en Guatemala ${ }^{10}$ que denunció la violencia sexual sistemática del ejército en contra de mujeres mayas en marzo de 2010 (MACLEOD 2020; CROSBY \& LYKES, 2011). Todos ellos han tenido una importante repercusión a nivel político al denunciar públicamente actos atroces y de lesa humanidad, si bien son principalmente tribunales éticos sin obligación judicial. Macleod señala que los Tribunales de Conciencia son eventos emblemáticos de gran poder simbólico que consiguen tener un impacto masivo por que evidencian tratos crueles e inhumanos y revelan el manto de

caso de Guatemala ver MACLEOD op cit y también CROSBY \& LYKES 2011)

${ }^{8}$ Primera Corte Popular de Mujeres del COPINH, 21 dic. 2010; https://copinh.org/2010/12/1ra-corte-popular-demujeres-del-copinh-la-esperanza-21-de-diciembre-2010/ impunidad que protege a los criminales (MACLEOD op cit).

Los Tribunales de Conciencia ponen en el centro a las víctimas y su palabra, por ello el testimonio es el principal instrumento para visibilizar agravios y daños que difícilmente son considerados en el proceso judicial, y menos de manera pública. Los testimonios en estos espacios revelan el drama humano que aqueja a personas que son violentadas en su integridad o la de sus seres queridos, pero también potencian la agencia de las víctimas y de sus familiares y con ello el valor para hablar de sus agravios desde lo profundo del corazón; lo que suele desestabilizar pactos institucionales. En ese sentido Alison Crosby \& Brinton Lykes señalan que "el testimonio en contextos de graves violaciones a derechos humanos es una construcción sociopolítica, cultural y de género que es relacional" (CROSBY \& LYKES 2011: 458). Es decir, responde a objetivos específicos, en tramas de poder que se activan en un contexto particular para llegar a un determinado público. No son por tanto actos neutrales ni predeterminados. Pero sobre todo con el testimonio se busca escuchar a las víctimas y sus verdades y no imponer significados previos que predefinan

\footnotetext{
9 Ver Tribunal Simbólico contra la violencia sexual en el conflicto armado en Colombia, 28 de septiembre 2011; https://verdadabierta.com/el-fallo-simbolico-de-laviolencia-sexual-en-el-conflicto/

${ }^{10}$ Ver:http://publ.hegoa.efaber.net/uploads/pdfs/207/Ni_olvi do,_ni_silencio.pdf?1488539728
} 
el daño y sus consecuencias. En este sentido podría decirse que hay una diferencia entre el testimonio en Tribunales de Conciencia y el testimonio en el proceso judicial; en estos últimos, incluso en el nuevo sistema acusatorio que pone en el centro la oralidad, la formalización de la ley termina por imponer criterios que silencian las voces de las víctimas (SIERRA FAJARDO en prensa); mientras en los TC el testimonio es el centro del ritual político lo que permite que la víctima tome la palabra.

El gran reto para las defensoras en el marco de los Tribunales es rebasar la racionalidad jurídica del proceso judicial a fin de permitir que las visiones sociales del daño y los sentidos de justicia de las víctimas puedan visibilizarse, aún y a pesar de los contextos donde sistemáticamente sus vivencias $\mathrm{y}$ experiencias son desdeñadas y no oídas. En el caso de los Tribunales de Conciencia que involucran a mujeres indígenas el escenario se complejiza porque hay que incorporar la dimensión intercultural y de género en el performance del Tribunal. Esto significa un esfuerzo especial para facilitar la participación de actores diversos como es el caso de intérpretes, traductores, peritos, etc.

Desde hace ya tres años (2018), el Centro de Derechos Humanos de la Montaña Tlachinollan, impulsa un Tribunal de Conciencia para visibilizar las graves violaciones a los derechos humanos de las mujeres indígenas. Estos Tribunales de Conciencia son espacios extrajudiciales de carácter simbólico que ponen en acción una ritualidad política para evidenciar la falta la acción pública y lo que consideran violaciones a los derechos humanos que impiden el acceso a la justicia; los testimonios son narrativas que introducen otros lenguajes y lógicas culturales. Se genera en este sentido un doble efecto: por un lado, los testimonios permiten que las víctimas narren los hechos y destaquen el sentido principal de su agravio en sus propios términos; y por otro lado, salen a relucir las ideologías de género arraigadas que naturalizan la opresión de las mujeres y como estas juegan en los operadores judiciales. No basta sin embargo el testimonio de la víctima sino es acompañado de su contextualización para hacerlo comprensible a un público amplio; de ahí que resulta central el acompañamiento y el trabajo reflexivo que hacen las abogadas $\mathrm{y}$ defensoras de Tlachinollan como conocedoras de las problemáticas. Son ellas las que traducen los testimonios a un lenguaje de derechos y las que actúan como bisagras para potenciar los reclamos y las demandas de justicia. La intervención de las abogadas facilita también la identificación de las formas sistémicas en que las instituciones del Estado faltan a su obligación de protección y quehacer de justicia. Un trabajo de documentación fino y sistemático a cada uno de los casos les asegura 
a las familias contar con un acompañamiento comprometido por parte de Tlachinollan.

\section{Violencias estructurales, despojo y macro-criminalidad en Guerrero}

Guerrero es un estado donde la criminalización de los movimientos sociales y las luchas de resistencia de las organizaciones sociales indígenas y gremiales tienen una larga historia (BARTRA, 1996). Desde hace ya varios años, la Montaña Alta donde se ubica el municipio de Tlapa de Comonfort, ha ganado relevancia como centro político y económico regional donde la producción de la amapola dinamiza en buena medida el mercado interno, al mismo tiempo que concentra la presencia de fuerzas militares y de seguridad pública (desde los años 80s) en el marco del combate al narcotráfico (TLACHINOLLAN, 2018). El municipio de Tlapa está cruzado por una gran conflictividad social derivada, entre otros aspectos, de políticas de seguridad que pretenden controlar el territorio pero que en realidad criminalizan la pobreza (MORA, 2017); por eso, organizaciones sociales, religiosas y de derechos humanos se arraigaron en esta región -desde los años noventas- para enfrentar la represión y los abusos a la población indígena y campesina (ESTRADA, 2009).
Tlapa es municipio pluriétnico con un alto porcentaje de población indígena, de alrededor de un 56\% (SNIM, 2010). Se constituye de población nahua, na'savi, me'phaa y mestiza organizadas en jerarquías raciales bajo el control caciquil de elites políticas (NICASIO, 2017). Hombres y mujeres de esta región se dedican a labores para la economía doméstica que van desde el cultivo de granos básicos, la venta de artesanías, la producción de café hasta la migración laboral agrícola, entre otras actividades. Los altos índices de marginalidad económica hacen de Tlapa una zona expulsora de mano de obra migrante a los Estados Unidos, pero también a los campos agrícolas de estados del norte y centro del país, especialmente Sinaloa, Morelos y San Luis Potosí. El flujo de jornaleros que migran temporalmente con sus familias tiene efectos en la organización comunitaria y en el tipo de vínculos que las arraigan localmente (HERRERA ANAYA, 2018; CANAVAL y FLORES 2004).

En el contexto reciente, Tlapa se ha vuelto uno de los municipios de Guerrero que atraviesa la más severa crisis de violencia y de inseguridad, con niveles alarmante de asesinados, de desplazamientos y desapariciones forzadas. La Montaña vive de manera exponencial los efectos de la violencia del crimen organizado que tiene amenazada a la población y que ha impuesto 
diversas formas de control territorial ilegal. El tejido comunitario se ha visto gravemente afectado por los efectos sociales de diversas actividades delincuenciales como la prostitución, negocios de trata, desaparición forzada de personas, trasiego de droga $\mathrm{y}$ extorsión. Para poder llevar acabo todas estas actividades ilegales y violencias el crimen organizado opera en colusión con las autoridades de diferente nivel (municipal, estatal y federal), constituyendo un estado de franca macro-criminalidad.

El informe del Monitor Civil de la Policía y de las Fuerzas de Seguridad en La Montaña da cuenta de la sistemática violación de derechos humanos cometidos por las fuerzas de seguridad pública en contra de pobladores de la región de la Montaña (MOCIPOL, 2011). El informe documenta las formas de actuación de las policías ministeriales a nivel municipal que en concierto con el mandato federal de seguridad frente el crimen organizado hace el trabajo de control micro-local a través de métodos extrajudiciales como la detención ilegal y la extorsión de las y los ciudadanos de los municipios de la Montaña, una mayoría indígena. Aunada a esta dimensión de control policiaco, los territorios de la Montaña se encuentran bajo el asecho de empresas transnacionales interesadas en sus recursos naturales, como el agua, los minerales y los bosques que junto con el crimen organizado aumentan la vulnerabilidad de las comunidades indígenas (TLACHINOLLAN 2017).

En términos de lo que particularmente refiere a la violencia de género en el estado de Guerrero, desde el año 2008 las organizaciones estatales feministas han observado el incremento de homicidios dolosos de mujeres que espejea los índices de muertes violentas de hombres, presumiblemente ligadas al crimen organizado y la guerra contra las drogas (FIGUEROA y SIERRA, 2020). Por ejemplo, el Observatorio de Violencia Contra las Mujeres "Hannah Arendt" elaboró un informe de homicidios dolosos de mujeres del estado de Guerrero (2005-2015). El informe de OVICOM (2015) divide el registro de notas periodísticas y casos reportados por la fiscalía del estado sobre violencia feminicida en dos decenios, del 1994-2004 y del 20052015. De esta división temporal refiere a dos tendencias: Un primer periodo que va del 1994-2004 que contabiliza 318 muertes violentas de mujeres por parejas y familiares cercanos. Se trata de muertes que acontecen prioritariamente en el ámbito doméstico. Para el segundo periodo que va del 2005-2015 donde el total de muertes violentas de mujeres se disparó a 1, 329. Este segundo decenio OVICOM lo inicia con una nota dramática del 2005 donde por primera vez en Guerrero se dieron 120 asesinatos de mujeres en un 
año, de los cuales, 7 fueron mujeres no identificadas debido a la destrucción de sus rostros y la descomposición de sus cuerpos.

Los observatorios estatales de violencia de género siguen recurriendo a las estadísticas oficiales sobre homicidios dolosos porque a su juicio es el delito que mejor refleja los índices de mortalidad de mujeres por causas violentas. En el 2010 el código penal estatal incluyó el delito de feminicidio, pero según las defensoras de la Montaña sólo el $10 \%$ de los homicidios de mujeres son tipificados como feminicidio pues requieren del oficio de fiscales especiales para abrir la cartera de investigación sobre los casos (TLACHINOLLAN, 2019). ${ }^{11}$

En el 2017 se declaró la Alerta de Violencia Género (AVGM) ${ }^{12}$ en el estado de Guerrero, producto de una amplia presión de organizaciones feministas para exigir al Estado definir medidas públicas dirigidas a atender los feminicidios. Los municipios indígenas de Tlapa, Ometepec, Ayutla y Chilapa (recién incorporada en 2018) forman parte de esta AVGM. Los municipios de la Montaña presentan menores índices de mortandad femenina que localidades más grandes como Acapulco, Chilpancingo, o el

\footnotetext{
11 Ver: http://www.tlachinollan.org/comunicado-justiciaolvidada-la-violencia-de-genero-en-la-montana-deguerrero/?fbclid=IwAR0Yu-

X65ygw0dIw6UgnoYdGM_c3YYqV5OhiWrSbZo1bRGhh-eAKhadwos

12 La Alerta de Violencia de Género contra las Mujeres (AVGM) es un mecanismo implementado por el gobierno
}

mismo Iguala (FIGUEROA, 2019), pero las especialistas regionales en la documentación consideran que hay un sub-registro debido a la marginalidad social de los territorios rurales e indígenas.

El SESNSP indica que en lo que va de enero a mayo del 2020 han contabilizado a nivel nacional 1,233 homicidios y 375 feminicidios de los cuales, 64 homicidios y 9 feminicidios han acontecido en Guerrero, correspondiendo 5 a los municipios de la Costa-Montaña. Cerraríamos diciendo que la violencia extrema contra mujeres es registrada bajo la figura de homicidio doloso y feminicidio.

En la Montaña donde se ha declarado la Alerta de Género (Chilapa, Ometepec, Tlapa y Ayutla) se constata el incremento de la inseguridad y del crimen organizado que pesa sobre la población. Dicha situación de violencia extrema impacta también a las estructuras comunitarias que se ven sometidas a nuevas lógicas de control afectando de manera particular a las mujeres y los niños (FIGUEROA y SIERRA op cit). Este contexto explica el recrudecimiento de la violencia de género en las comunidades y el hecho que las mismas estructuras comunitarias no están pudiendo contener las

de México con el fin de «enfrentar y erradicar la violencia feminicida en un territorio determinado. La AVGM se estableció en 2007 con la creación de la Ley General de Acceso de las Mujeres a una Vida Libre de Violencia. 
violencias como ha sucedido en regiones cercanas (SIERRA 2018; LEY, MATTIACE y TREJO 2019). La situación de inseguridad se monta sobre las estructuras patriarcales comunitarias incrementando la vulnerabilidad de las mujeres, es decir, un "entroque patriarcal", parafraseando a Paredes (2008), que permite referirnos a los efectos reforzados de la dominación masculina en comunidades indígenas.

Este contexto de incrementada vulnerabilidad se traduce en un aumento de las tensiones sociales al interior de los grupos domésticos y los espacios comunitarios, lo que propicia por ejemplo disputas por la pensión alimenticia, o el que a las mujeres se les despoje del patrimonio familiar - como lo es su casa - en casos de separación, o que se incremente la violencia física ante situaciones diversas que afectan también a los hijos, entre muchas otras tremendas consecuencias que aumentan en un contexto de debilitamiento de la autoridad comunitaria. En la mayoría de las disputas domésticas está presente el alcohol que eleva el nivel de agresividad y el arraigo de ideologías patriarcales que naturalizan la autoridad masculina, así como el control sobre el cuerpo y los movimientos de las mujeres. La violencia que las mujeres enfrentan no se restringe al daño físico, sino que involucra una dimensión socio-cultural y emocional donde la palabra de la mujer vale menos que la del hombre, lo que se justifica en el entramado normativo comunitario (SIERRA 2017; MORA, 2017b; CROSBY y LYKES, 2011); sucede también que los acentos que ponen las mujeres sobre las vulnerabilidades que las aquejan no necesariamente son los mismos que los definidos por los hombres y esto puede ser la fuente de discrepancias y conflictos, como ocurre por ejemplo con el uso de los recursos de la economía doméstica, o bien con la distribución de las tareas familiares.

Son estas las realidades que se visibilizan en los casos presentados en los Tribunales de Conciencia organizados por Tlachinollan. El gran reto es considerar la intersección de las violencias - cultural, estructural y de género - tal como es fraseada por las víctimas y articulada en el discurso jurídico para hacer exigible su verdad ante la ley y las instituciones.

\section{EI Tribunal de Conciencia y mujeres indígenas. Visibilizando la cadena de obstáculos y de impunidad.}

Los Tribunales de Conciencia que ha impulsado el Centro de Derechos Humanos de La Montaña Tlachinollan son una estrategia más para visibilizar la falta de acceso a la justicia y las violaciones graves a los derechos humanos que enfrentan las mujeres indígenas por su condición de clase, étnica y de género. 
Otras estrategias han sido la denuncia ante las instancias internacionales de DDHH, acompañando casos de violencias extremas, en contra del Estado mexicano por violencia militar castrense, en el caso de mujeres me'phaa violadas por militares (HERNÁNDEZ CASTILLO, 2017). Otra más ha sido la difusión de los casos ante figuras internacionales relevantes como sucedió con Victoria Tauli-Corpuz, Relatora de la ONU por los Derechos de los Pueblos Indígenas, en su visita a Tlapa, Guerrero, el 11 de noviembre de 2017, para conocer de viva voz los reclamos de hombres y mujeres indígenas por la violación a sus derechos individuales $\mathrm{y}$ colectivos. ${ }^{13}$ De esta manera, los Tribunales de Conciencia se insertan en el conjunto de acciones impulsadas por el Centro de Derechos Humanos Tlachinollan para denunciar ante la opinión pública la impunidad y las condiciones de vulnerabilidad extrema que afectan las vidas de las mujeres indígenas y de sus comunidades. Son parte de una defensa integral y ampliada para la búsqueda de justicia.

El 6 de marzo de 2017, El Centro de Derechos Humanos Tlachinollan instaló el primer Tribunal Conciencia en la ciudad de Chilpancingo llamado "El Rostro Luminoso de la Justicia”. Posteriormente en los años subsiguientes se realizaron dos Tribunales

\footnotetext{
${ }^{13}$ La Relatora por los Derechos Indígenas por la ONU, Victoria Tauli-Corpuz, visitó la Montaña de Guerrero el 11 de noviembre de 2017 para tener un diálogo con los
}

más: el segundo "Con nuestras Voces derrumbaremos el Sistema Patriarcal" (8 de marzo 2019) y el tercero "Telar de Historias, de Sueños y Tragedias" (6 de marzo 2020), todos con el fin similar de exigir justicia, verdad y reparación en contextos de impunidad institucionalizada. Los tres Tribunales han tomado como eje central la violencia hacia las mujeres indígenas y el cuestionamiento a la cultura patriarcal, arraigada en las instituciones y en la sociedad. El propósito expreso es denunciar la cadena de obstáculos que enfrentan las mujeres para acceder a la justicia debido a la discriminación estructural-patriarcal-institucional que las afecta y con ello visibilizar la responsabilidad de las autoridades judiciales y funcionarios públicos. Con este fin se convocó a gente de la sociedad civil, observadoras de derechos humanos, abogados aliados, especialistas en defensoría e integrantes del poder judicial para escuchar de viva voz el relato de las violencias $\mathrm{y}$ atropellos hacia mujeres indígenas.

Los TCs se han realizado en el auditorio principal del Poder Judicial en la ciudad de Chilpancingo, el corazón de la capital del estado de Guerrero. Una sala de corte semicircular, rodeada de fotos de los próceres de Guerrero, en su mayoría hombres que confirma simbólicamente el sesgo patriarcal de quienes hacen la historia. Se trata

pueblos indígenas de la región. Ver. https://redtdt.org.mx/?p=11621. 
sin duda del lugar clave políticamente para visibilizar la falta de justicia hacia las mujeres indígenas en el estado. Como referimos anteriormente, los TCs son un perfomance que al poner en primer plano a las víctimas y sus testimonios desnudan los procesos judiciales y obligan a reconocerlas en su persona y a escuchar sus voces, yendo más allá de la frialdad de la ley en el espacio judicial. Los testimonios presentados son emblemáticos en la medida que representan la voz de muchas otras mujeres que viven experiencias similares; por eso en las intervenciones de estas mujeres violentadas fue recurrente escucharlas decir: "no queremos que otras mujeres sufran como nosotras". Desde su dolor denunciaron violencias múltiples que se ensañan en sus cuerpos, y con ello hicieron eco de muchos otros cuerpos ultrajados.

Los casos presentados ante el TC son representativos de los que cotidianamente llegan al Centro de Derechos Humanos de la Montaña, generalmente después de haber acudido al sistema judicial y encontrar que les cerraron las puertas. ${ }^{14}$ Todos ellos responden a patrones de violencia extrema y revelan distintas irregularidades en el proceso judicial o en el trato institucional frente al personal de salud: entre otras, descalificación de las mujeres por parte de

\footnotetext{
14 Agradecemos a la Neil Arias Virginio, abogada de Tlachilollan, la información brindada sobre los casos que se presentaron en los tres Tribunales de Conciencia.
}

fiscales o jueces que pueden poner en riesgo su integridad física; negligencia médica que ha significado la muerte de mujeres al momento de dar a luz o daños permanentes para ellas o sus hijos (violencia obstétrica); criminalización de las mujeres por atreverse a denunciar y su re-victimización; entre otras acciones que violan sus derechos humanos. Así también la vulnerabilidad de las víctimas $y$ sus familiares se incrementa ante las exigencias del sistema penal acusatorio de presentar evidencias y buscar testigos, lo que para ellas significa una enorme carga física, económica y emocional difícil de cumplir. Los casos revelan así mismo a un patrón de violencia de género en el que prevalecen las relaciones cercanas con el agresor, en contextos de alta marginalidad y de dependencia familiar. Lo descarnado de las violencias que viven las mujeres indígenas revela también la precariedad de sus vidas y de sus comunidades cada vez más afectadas por crisis diversas que incrementan su vulnerabilidad.

Los Tribunales son una oportunidad para denunciar el desvío de la justicia del sistema penal. Ante un sistema judicial corrupto y discriminador la apuesta es recuperar el sentido reparador de la justicia y no solamente la dimensión punitiva del proceso legal; por ello, recurrir a los TC se 
ha convertido en un recurso más para evidenciar los obstáculos y la cadena de violación de derechos que enfrentan las mujeres na'savi, me'phaa, ñancue ñomndaa y nahuas de la Montaña de Guerrero en su demanda de justicia. Son en ese sentido una estrategia extrajudicial - inserta en una ruta de defensa legal - para visibilizar la cadena de impunidad del proceso judicial, lo que involucra una importante movilización de actores, recursos y las garantías para llegar a las distintas audiencias.

Como actos rituales los TC organizados por Tlachinollan siguen una misma estructura formal que pone en el centro el testimonio de las víctimas y la participación de juezas. En un segundo plano se encuentran las audiencias, integradas por funcionarios que son destinatarios de las denuncias: operadores del poder judicial, del sistema de salud pública, de la Comisión Estatal de Derechos Humanos, así como el público en general. En este público suelen estar presentes organizaciones no gubernamentales, académicos, organizaciones indígenas, etc., que atestiguan el juicio.

El TC toma forma en las interacciones institucionales lo que significa una distribución ordenada y guiada de la palabra y en general involucra tres momentos: inicia con una formal introducción para destacar la relevancia y los objetivos del Tribunal, que suele realizar de manera solemne Abel Barreda, el director de Tlachinollan - personaje emblemático en la lucha por los derechos humanos en Guerrero. A esto le sigue la presentación de los casos y su contextualización para situar la problemática y el estado del proceso judicial, tarea que realizan las abogadas y defensoras del Centro. Continúa el testimonio de las víctimas y finalmente intervienen las juezas convocadas a escuchar los testimonios y dar su veredicto con relación a las graves violaciones a los derechos humanos y la violencia patriarcal. Lo más esperado del Tribunal es sin duda la participación de las víctimas, sean las víctimas directas o sus familiares, quienes han debido sobrepasar muchos obstáculos para que finalmente su voz sea escuchada. Dado que muchas de ellas no hablan español su testimonio lo hacen en su propia lengua, generalmente me'pha, náhuatl o t'un savi, y esto alarga los tiempos y genera una tensión especial que evidencia la disposición de la audiencia a la escucha. Son las colaboradoras de Tlachinollan, ellas mismas hablantes de la lengua indígena, quienes realizan la traducción para garantizar la interlocución de las juezas con las víctimas.

Las expertas en los tres tribunales que conformaron el jurado han sido mujeres feministas -activistas, periodistas $y$ académicas - quienes condenaron los obstáculos a la justicia para las mujeres, destacaron la importancia de nombrar las violencias extremas y pusieron en relevancia 
los derechos violados y la legitimidad del reclamo. Algunas también argumentaron desde una perspectiva de diversidad cultural para destacar el significado de dichas violaciones en el marco de los sistemas normativos y sus cosmovisiones.

La alta dosis de perfomance de los Tribunales, por su fuerza simbólica y ritual, tiene efectos en las audiencias y público presente. Son efectivamente actos de gran poder simbólico sustentados en el derecho humanitario que desnuda agravios y apela a la justicia más allá de la ley. ¿Qué significa la presencia de las víctimas en Sala Magna del poder judicial? Por un lado, revela las grietas que se abren en el proceso hegemónico donde los subalternos hacen sentir su presencia y desnudan al poder (ROSBERRY 2007). Pero por otro lado visibilizan de manera descarnada su vulnerabilidad al flanquear una liminalidad y decir públicamente su agravio. El testimonio de las víctimas detona emociones que potencian el mensaje simbólico de la denuncia, al expresar su visión social del daño y lo que buscan como justicia y reparación. Como en la mayoría de los TC lo importante es entonces el efecto simbólico ya que ni los testimonios ni los veredictos tienen fuerza de ley ni garantías de cumplimiento. La apelación al derecho en estos contextos es sin embargo un potente mecanismo para develar estructuras profundas de discriminación y desigualdad que desestabilizan las certezas del poder; $\mathrm{y}$ en esa medida generan en las víctimas esperanza y activan su agencia social. El derecho revela aquí su fuerza simbólica como conjuro, en palabras de Julieta Lemaitre (2009).

\section{Rompiendo el silencio ante el cúmulo de violencias. La fuerza del testimonio en la búsqueda de justicia.}

"Nosotros denunciamos allá (en el Tribunal de Conciencia) porque era necesario decir qué está pasando con los jueces, qué está pasando con los ministerios públicos que han citado a las mujeres, las amedrentan, (...) las acusan, las prejuzgan, las estigmatizan, las discriminan, las revictimizan"

Con estas palabras Neil Arias Virginio, abogada de Tlachinollan, sintetiza el tortuoso camino que significa para las mujeres indígenas acceder a la justicia ordinaria y con ello la necesidad de buscar otros foros como los del TC para denunciar la impunidad y la violación sistemática a los derechos humanos. El arduo trabajo de defensa que las abogadas realizan cotidianamente se enfrenta a oídos sordos en operadores judiciales - hombres y mujeres- que por vicios del sistema y por su propia mentalidad racista y patriarcal difícilmente se interesan en ir a fondo de los hechos, aletargan la justicia y dificultan su labor de defensoras. Hemos tenido la oportunidad de conversar en distintos 
momentos con Neil Arias sobre su experiencia en la defensa de los casos, además de escuchar su intervención experta en los Tribunales lo que revela su elocuencia, compromiso y agudeza para presentarlos.

En lo siguiente nos referimos a dos de los casos presentados en los TC organizados por Tlachinollan que revelan el conjunto de obstáculos que enfrentan las mujeres indígenas para denunciar violencias extremas, así como su convicción de buscar justicia. Nos basamos en los testimonios vertidos en los tres Tribunales de Conciencia, en las fichas técnicas de los mismos y recuperamos los comentarios hechos por las defensoras para contextualizarlos y señalar las graves violaciones a los derechos humanos involucradas.

\section{A.) Despojo patrimonial y violencia sexual. Complicidades patriarcales}

"Yo me llamo Laura (anónimo) aquí vine, porque quiero que se haga justicia, tenía mucho miedo para hacer estas cosas (denunciar públicamente) pero ahora ya no, ya tengo más valor porque sé que lo que yo hice no está mal" (Trad. del me'phaa)

El testimonio de Laura revela su voluntad de hacer público su agravio para exigir justicia. Venciendo dificultades materiales y subjetivas ella decide denunciar a su agresor, su ex - pareja, por violencia, despojo y violación. Su testimonio habla del engrane de las ideologías de género que opera a distintas escalas, que van de lo doméstico al espacio judicial, y sus efectos en la generación de múltiples violencias. Laura da cuenta también de los obstáculos que enfrentó para acceder a la justicia y de su decisión de defenderse.

Laura, es una mujer na'savi, proveniente de la comunidad de Ayotzinapa, municipio de Zitlata, Guerero. Es jornalera agrícola y trabaja temporalmente en los campos de Sinaloa, a donde suele desplazarse por varios meses junto con su familia, como lo hacen muchas otras familias de la Montaña. De esta manera consiguió los recursos económicos necesarios para el sustento familiar y hacerse de una casa. Laura vivió con su esposo durante casi veinte años, durante los cuales procreó tres hijos. Durante varios años vivió violencia doméstica pero el conflicto escaló cuando él decidió meter a otra mujer a su casa; en un primer momento ella se vio obligada a permanecer para defender su hogar hasta que él decidió correrla de forma violenta. Posteriormente el esposo denuncia a Laura por lesiones -una supuesta agresión física por parte de Laura a la nueva pareja del esposo- en el Ministerio Público en Tlapa y como resultado de un proceso judicial amañado a ella se le sentencia a un año de prisión. Con el apoyo de las abogadas de Tlachinollan el asunto es 
apelado y pasa a una segunda instancia que finalmente falla a su favor. En otro proceso judicial Laura presenta una denuncia por despojo y violación contra el papá de sus hijos; en un proceso lleno de irregularidades no se acredita la violación.

En la exposición del caso ante el Tribunal de Conciencia en Chilpancingo, la abogada de Tlachinollan, destaca la indolencia de la justicia para Laura y las condiciones de discriminación que la afectaron: la abogada refiere distintos momentos en los que Laura fue víctima de violencia institucional. Señala que la Jueza durante el primer juicio descalificó a Laura e hizo escarnio de su dolor diciéndole de forma burlona: “¿Quieres ver a tú amor?; ¿quieres platicar con él?; "a sabiendas de su conflicto". La jueza no solo se dirigió a ella de forma irrespetuosa y burlona, sino que la sentenció a un año de prisión y le impuso una multa por delito de lesiones. Todo ello afectó mucho a Laura pues no creyeron en su testimonio según el cual ella estaba trabajando en Sinaloa el día que supuestamente ocurrió la agresión a la nueva pareja del esposo. Fue entonces que Laura buscó apoyo en Tlachinollan para la apelación de la sentencia en una segunda instancia que afortunadamente falló a su favor al probar que la jueza no valoró sus pruebas y se demostró que su delito fue fabricado. Laura inició otro juicio en donde denunció al esposo por despojo y violación, quién la agredió sexualmente y le rompió la dentadura. En este segundo juicio, el juez no acreditó el delito de violación por considerar que no se garantizó la fidelidad de la prueba. De nuevo se tuvo que apelar la sentencia, pero en esta ocasión tampoco los magistrados valoraron el testimonio de Juana, por lo que las abogadas interpusieron un amparo directo que seguía pendiente (6 de marzo 2018).

¿Qué significa para Laura que se haga justicia?, en un proceso plagado de irregularidades. A continuación, introducimos algunos trozos de su testimonio (traducción del mep'haa):

"Yo me llamo Laura aqui vine, quiero que se haga justicia, tenía mucho miedo para hacer estas cosas, pero ahora ya no, ya tengo más valor porque sé de lo que yo hice no está mal. Lo que me hicieron me hizo mucho daño; yo tenía una casa, vivía bien con mi pareja, pero ahora si que ARM decía que él es hombre, que él era el que mandaba a la casa, que él tenía derecho de meter la mujer. Él decidió tener en donde era mi casa a la mujer, y que yo no tengo derecho de estar ahi en mi casa, que la que tiene derecho es la mujer, y yo trabajé mucho para hacer esa casa con él, era igual de mis hijos. Ahora yo tengo que luchar, trabajar, salir adelante, mantener a mis hijos, mis tres hijos que tengo, y gracias a dios ya están grandes (... ). He luchado para salir adelante yo sola, ni me ha ayudado a mantener, fui violada. Todo eso lo que me pasó ya está, y hice la demanda y ahorita está libre y yo lo que quiero es justicia. Sufrí mucho, y a veces yo pienso que somos mujeres 
que como que no nos escuchan, pero también vienen personas de lejos que sí nos escuchan. A veces me pongo más triste, porque tengo que trabajar para salir adelante, hacer otra casita, aunque sea pequeña donde voy a vivir otra vez con mis hijos, y yo lo que yo quiero es justicia, que se me haga justicia, porque ahora tengo miedo de que, si me pasa algo porque él está libre, quiero justicia y eso es lo que quiero (6 de marzo del 2018)

El testimonio de Laura da cuenta de la cadena de agravios que vivió en el ámbito doméstico y el abuso sexual cometido por su esposo. Destaca el gran esfuerzo que invirtió en trabajar de jornalera para construir una casa y mantener a sus hijos, por lo que considera injusto que el hombre además de abusar de ella se apropie de sus bienes. Especialmente, se siente amenazada y tiene miedo de posibles agresionesporque a pesar de la demanda de violación el señor está libre. En su narrativa sin embargo el énfasis de queja no es la violación sino la pérdida de su patrimonio, por lo que insiste en su derecho a recuperar su casa, producto de su esfuerzo. La casa se convierte en foco de la disputa ante la necesidad de garantizar a sus hijos un techo para vivir.

“(..) él me quería sacar de allí y él decía: "lo que tú hagas nadie te va a creer, porque tú eres una chismosa y el día que yo quiera sacarte te saco a patadas, y te voy a sacar las cosas", pues eso es lo que hizo". "Yo voy a hacer justicia con mis manos"(...) O sea, yo sufrí esas cosas y él me hace todo lo que me hace, me demanda para que él se quede con la casa, y al final se quedó con toda la casa"

El testimonio de Laura es una muestra de la cadena de obstáculos que enfrentan las mujeres indígenas en los procesos judiciales; no solamente la jueza minimizó los hechos, sino también en segunda instancia los magistrados no reconocieron el delito de violación por supuestas inconsistencias en las pruebas del caso, no creyeron en su testimonio, y más bien lo banalizaron. De acuerdo con información de las abogadas, de manera grosera y abusando de su poder, los magistrados del Tribunal de Justicia en la Sala Penal de Chilpancingo señalaron que: "las mujeres de la Montaña son mujeres fuertes y ellas sí tienen la capacidad para defenderse de una agresión"; con lo que descalificaron su denuncia y dejaron ver que ella pudo evitarlo. De esta manera los funcionarios judiciales de alto nivel recurrieron a estereotipos de género y de discriminación para descalificar a Laura cuando se esperaría que juzguen con base en los más altos estándares de derechos humanos, con perspectiva de género y de diversidad cultural, a lo cual están legalmente obligados.

Se refuerzan así las difíciles condiciones que enfrentan las mujeres indígenas al buscar acceder a una justicia que las discrimina y las re-victimiza por atreverse a alzar la voz y denunciar la autoridad masculina. Tales hechos son aún más 
violentos simbólicamente cuando la autoridad judicial es una mujer, como fue el caso de la jueza de Primera Instancia que llevó su proceso en Tlapa. Por ello, durante el TC en Chilpancingo, Martha Dillan, activista feminista, ${ }^{15}$ destacó que: "La jueza no te vio o no te quiso ver, para que quedaras invisible"

Este caso pone en la mesa un conjunto de violencias múltiples que se cruzan en la vida de las mujeres indígenas involucrando violencias cotidianas, domésticas y sexuales, patrimoniales e institucionales junto con violencias racistas que denigran a las mujeres indígenas de la Montaña. Visibilizan asimismo la situación de vulnerabilidad estructural que cierran sus opciones de vida y las enganchan a círculos de violencia que resulta difícil de romper. Laura tampoco tuvo el apoyo de la autoridad de su comunidad y ha debido asumir la responsabilidad de mantener a sus hijos, por ello sigue insistiendo que se castigue a su ex-esposo y se garantice el derecho a recuperar su propiedad. La violencia patrimonial que vivió Laura no solo significó perder la casa, sino además implicó que se le fabricara un delito que no cometió y se le impusieran penas de cárcel. Es decir, en los procesos judiciales pesan ideologías patriarcales reforzadas por un racismo

\footnotetext{
15 Las defensoras feministas de derechos humanos participantes como juezas de conciencia en el TC del 6 de marzo del 2018 fueron Marta Dillon (activista feminista argentina), Regina Tamés Noriega (directora
}

judicial que contribuye a subordinar a las mujeres indígenas y socavar sus derechos. Desde la visión de Laura, el sentido social del daño solo se comprende considerando el contexto de los hechos narrados y las justificaciones que dan validez al conjunto de su denuncia; para Laura lo que está en juego es su patrimonio y el bienestar de sus hijos, lo demás, incluyendo la violación participa de una secuencia de hechos.

Para Laura poder hablar en el espacio del TC fue liberador en la medida que pudo decir su verdad y ser escuchada, aún si su intervención fue acotada y a través de una traductora. Por eso de manera enfática agradece a las abogadas de Tlachinollan: "me ha apoyado en todo y hasta aquí, porque antes yo no quería vivir, yo decía "pues si no hay justicia yo ya no quiero vivir", pero después ya yo salí adelante". Como lo enfatizaron las juezas que dieron su veredicto en el Tribunal de Conciencia: "Laura es una guerrera que está dispuesta a defender su dignidad y que busca los caminos para alcanzar justicia y no quedarse callada" (6 de marzo, 2018). Como ella muchas otras mujeres indígenas hacen el esfuerzo cotidiano de exigir justicia, aún a costa de muchas resistencias dentro y fuera de sus comunidades y familias.

del Grupo de Información en Reproducción Elegida, GIRE), y Anayeli Pérez Garrido (Observatorio Ciudadano Nacional del Feminicidio). 


\section{B.) Feminicidios en la Montaña.}

\section{Cúmulo de inseguridades y violencias.}

La muerte violenta de mujeres por razón de odio de género, tal como se define al feminicidio (LAGARDE, 2008), está presente en las comunidades de la Montaña desde hace tiempo, en la medida que involucra relaciones de poder imbricadas en costumbres que subordinan a las mujeres. Lo que es nuevo es la mercantilización del cuerpo de las mujeres en el contexto de la macro-criminalidad que se ha extendido en los últimos años en la región; tal es lo que revela el incremento en los delitos de trata, las violaciones y otras violencias extremas como las desapariciones forzadas (TLACHINOLLAN, 2018). La Declaratoria de Alerta de Género en el municipio de Tlapa, viene a confirmar que las violencias extremas y cotidianas se ensañan en el cuerpo de las mujeres en geografias racializadas donde la presencia del Estado está marcada por un alto nivel de impunidad y convivencia con el crimen organizado (MORA, 2017; FIGUEROA y SIERRA, 2020). Si bien el estado de Guerrero se distingue por los altos índices de homicidios dolosos de mujeres (SESNP, 2020), son pocos los casos catalogados como feminicidio en las regiones indígenas. El escaso registro oficial no significa que el fenómeno no exista, sino que hay un sub-registro, como antes referimos. Esta ha sido justamente unas de las luchas emprendidas por las abogadas de Tlachinollan que están comprometidas en visibilizar las muertes violentas de mujeres indígenas para que no queden impunes. Han sido ellas quienes han acreditado penalmente el primer feminicidio de una mujer indígena en la región de la Montaña, tarea ardua que ha significado una batalla titánica. Por casos como este Tlachinollan promovió el Primer Tribunal de Conciencia en Chilpancingo con el fin explícito de evidenciar la cadena de obstáculos que enfrentan las mujeres indígenas en su búsqueda de justicia, pero también para abonar a su decisión de romper el silencio.

\section{Testimonio de una muerte anunciada. Violencias feminicidas y violencias institucionales}

"Pido que no liberen a quien asesinó a mi hija" (Testimonio de Martina (anónimo), en lengua Me'phaa)

Martina es una mujer me'phaa de la comunidad de Loma Tuza, municipio de Acatepec, Montaña de Guerrero, que ha tenido el valor de dar su testimonio en tres audiencias de los TC que Tlachinollan ha organizado en Chilpancingo. La última vez que la escuchamos, el 6 de marzo de 2020, parecía tener más confianza y fuerza que en el Primer Tribunal, si bien el juicio por el feminicidio de su hija Carmen, aún se encuentra en proceso. Martina es una mujer delgada, que aparenta tener más de 60 años, 
hablante de me'phaa por lo que necesita traducción; no ha dejado de acudir a las sesiones de los Tribunales acompañada de su hija y de otros familiares, a pesar del desgaste físico y emocional que le significa.

Carmen, de 24 años, fue asesinada en una acción criminal organizada por su ex esposo como parte de una muerte anunciada. Semanas antes de la agresión, el señor a través de radios de comunicación personal buscaba apoyo de vecinos para agredir a su exmujer. La cólera del hombre se debió a que Carmen, le pidió una pensión de alimentos para sus dos hijas ante el síndico municipal -y ya antes ella había peleado la casa y los bienes- lo que él recibió como una afrenta a su autoridad masculina y prometió vengarse. Carmen vivió violencia doméstica durante cinco años. Dos niñas huérfanas son víctimas indirectas de este feminicidio.

$$
\text { Carmen fue violada }
$$
tumultuariamente, le cortaron las orejas y la golpearon brutalmente hasta quitarle la vida. El drama no queda ahí, se le suman las irregularidades que han plagado todo el proceso forense-judicial. El testimonio de doña Catalina en el TC ponen en evidencia las inseguridades a las que están expuestas las mujeres por cuestionar reclamar sus derechos.

A Carmen le falló la protección de la autoridad comunitaria ante las amenazas hechas públicas por su ex pareja. A las irregularidades procesales se agrega el contexto de vulnerabilidad de los familiares de la víctima, un núcleo familiar compuesto por sólo mujeres y que siguen sufriendo amenazas por parte del homicida y sus cómplices. Si bien para las abogadas defensoras lo prioritario es avanzar en la declaratoria del caso como feminicidio, que involucra una pena de 60 años, para las familiares de la víctima lo relevante es que el agresor no salga de la cárcel y evitar que las continúe amenazando. La madre, la hermana y las niñas huérfanas son quienes están expuestas a nuevas agresiones por parte de los acusados. Este caso revela un patrón recurrente de exclusión y racismo en el que opera el sistema judicial en regiones indígenas, que a su vez es reforzado por las lógicas patriarcales que atraviesan a la autoridad local y regional.

¿Cuál es el sentido principal del agravio? Aunado a la muerte violenta de Carmen que sucedió el 24 de agosto de 2014, resaltan de manera fehaciente las irregularidades del proceso pericial cuando la policía ministerial hizo las diligencias para levantar el cadáver: no sólo tardaron ocho días en presentarse en la comunidad, sino que les exigieron $\$ 8000$ pesos a las familiares para trasladarlo al Servicio Médico Forense (SEMEFO) y hacer la necropsia en Chilpancingo. Las mujeres decidieron no permitir que se llevaran el cuerpo y lo enterraron conforme a sus costumbres. Esto 
propició que se afectara una posible investigación judicial, y que las pruebas guardadas en el propio ataúd - como ropa y un pasamontañas de los asesinos- no fueran válidas. Como puede apreciarse los procedimientos judiciales para integrar la averiguación han estado plagados de fallas, empezando por la falta de peritos, retrasos, insensibilidades en el trato con los familiares y las acciones del abogado del inculpado han hecho que se alargue el juicio y se busque desacreditar el feminicidio. Afortunadamente gracias al buen oficio de Tlachinollan, el principal agresor ha sido detenido pero los dos otros cómplices siguen prófugos.

A continuación, referimos fragmentos del testimonio de doña Martina, mamá de Carmen,-que se dio en el seno del auditorio del poder judicial de Guerrero frente a un público observante, juezas expertas y las defensoras de Tlachinollan, quienes le dieron apoyo moral y tradujeron su intervención.

Martina $\div$ Mi hija murió en el año 2014 (el Primer Tribunal fue en marzo de 2018), por eso vengo ante ustedes a presentarme y a decirles que queremos justicia por lo que nos pasó. Y por la muerte de mi hija es por eso que nosotras andamos pidiendo por ella. Donde nosotras vivimos hay personas que nos amenazan por lo que estamos haciendo y nosotras queremos que a esas personas se les detenga para que nosotras podamos seguir nuestro camino; nos dicen en donde nosotras caminamos que va a haber venganza. Queremos que la persona que ahorita se encuentra detenida ahi se mantengan para siempre (...)
Más adelante incentivada por las intervenciones de las juezas de conciencia, Catalina da cuenta de la actualidad de las amenazas contra ella:

Martina: "el 7 de este mes de nueva cuenta me amenazaron $y$ quisieron matarme con un machete Lorenzo y Bartolo, los cómplices (del yerno). Era un miércoles aproximadamente como a las 4 de la tarde, yo había ido a la milpa para recoger un poco de mazorca que tenía y ahi justo me los topé”.

El testimonio de Martina revela que se siente amenazada en su comunidad; no sólo ha tenido que reponerse del dolor por el asesinato salvaje de su hija, sino que además ha tenido que asumir la crianza de sus pequeñas nietas. Por eso ella necesita tener la garantía de no ser amenazada y de que se haga justicia. En su declaración no habla de la palabra feminicidio, término que no pronuncia, pero sí que el culpable no salga de la cárcel: "que lo mantengan para siempre". Sus palabras dejan ver su enorme dolor y enojo por el crimen cometido, pero también el temor que le provocan las amenazas del ex-yerno, sabiendo que sí las cumple.

En una conversación Neil Arias, la abogada de Tlachinollan, destaca que en los cuatro años que llevan acompañando a víctimas de feminicidio los patrones han sido muy similares: (1) antecedentes de violencia 
doméstica; (2) previas denuncias de las víctimas ante alguna autoridad -ya sea al comisario municipal, síndico municipal, ministerio público-; (3) no hay recepción a sus demandas; (4) no hay medidas cautelares a su favor; (5) la institución judicial no garantiza el seguimiento de los casos:

"En Tlapa contamos con una ministerio público que da atención a los 19 municipios que conforman la región de la Montaña, igual carecemos de peritos para hacer las respectivas diligencias. Se carece de mucha infraestructura también para dar atención a estos casos, y otra de las cuestiones que es importante retomar es que en la mayoría de los casos de feminicidios que se dan aqui en nuestro estado es que justo las víctimas indirectas, los niños que quedan huérfanos, las niñas, cambian repentinamente su proyecto de vida porque el agresor ha sido la pareja o el padre" (N. A. Tlapa, 20.02.2017)

La abogada refiere a las condiciones precarias en las que opera el poder judicial en estas regiones, sin la infraestructura ni el personal adecuado para enfrentar realidades dramáticas como la de Carmen. Esto potencia los efectos de la exclusión y la desigualdad en las víctimas indirectas como son los niños, una de las grandes preocupaciones que salen a relucir en torno a estos casos. Finalmente, esta precariedad responde a políticas de Estado que reproducen la marginación de regiones donde imperan poderes fácticos y caciquismos como sucede en la Montaña.
Las juezas de conciencia que juzgaron el feminicidio de Carmen destacaron las múltiples violencias que se acreditan en torno a este feroz asesinato: violencia física, sexual, psicológica y económica que cometió su expareja por varios años; así como también una violencia institucional por el desvío de la justicia y más aún por tratarse de una mujer indígena pobre y marginada. Es decir, porque la justicia no consideró la perspectiva de género ni de diversidad cultural a lo cual están obligadas las autoridades judiciales a partir de la reforma al artículo primero constitucional y a las leyes referidas a una vida libre de violencia. Resulta aberrante que a pesar de que todas las mujeres víctimas denunciaron los hechos, fueron con la autoridad, según refiere Neil Arias “... ninguna hizo nada. Si hubieran medidas de protección muchas muertes se pudieran evitar. Sí tenemos derecho a vivir una vida libre de violencia" (2017).

Participar en el TC y sentirse acuerpada por otras mujeres en situaciones similares ha tenido un efecto positivo en Martina quien mantiene la esperanza de conseguir justicia. También es cierto que no es nada fácil para estas mujeres romper el círculo de la violencia y menos aún demandar derechos cuando sus condiciones de vida no les ofrecen medios para construir otro tipo de relaciones. A pesar de todo, para las víctimas y sus familiares es importante que su voz se escuche y llegue a las autoridades. Si bien no 
hay una garantía que con ello cambien las cosas sí desnudan al poder judicial y obligan a una respuesta. A casi siete años desde que se cometió el crimen no se ha conseguido la sentencia definitiva por feminicidio, lo cual garantizaría 60 años de condena.

En este caso sale a relucir un hecho que ha llamado poderosamente nuestra atención, el que se haya tratado de un crimen anunciado, es decir que fue planeado $y$ conocido por varios vecinos y la misma autoridad comunitaria, lo cual revela una complicidad patriarcal, pero también la fragilidad de instituciones comunitarias y sus autoridades que en otras circunstancias debieron intervenir. Por ello es importante reflexionar sobre el impacto de la inseguridad y la violencia en las regiones indígenas y sus afectaciones en las mujeres; y la urgencia de discutir estos dilemas con las propias autoridades locales como lo demandan las defensoras comunitarias (SIERRA 2017; FIGUEROA y SIERRA 2019).

\section{Conclusiones}

Acceder a la justicia para las mujeres indígenas - ya sea la estatal o la comunitaria - es una carrera llena de obstáculos difíciles de traspasar. En esta obstrucción juegan de manera central las ideologías de género que privilegian la dominación masculina incrustada en las costumbres comunitarias, y en las prácticas y mentalidades de quienes ejercen justicia. Esto resulta especialmente grave cuando la violencia patriarcal se interconecta con otras violencias estructurales que impactan a las comunidades indígenas, como es el racismo y la desigualdad económica, causando afectaciones específicas para las mujeres. Las narrativas aquí vertidas muestran la cadena de opresiones y vulnerabilidades que pesan sobre el cuerpo de las mujeres indígenas que no están encontrando atención en sus autoridades comunitarias así como tampoco en las instancias judiciales estatales que reproducen la discriminación hacia las mujeres. En este contexto es notable el trabajo comprometido de las abogadas y abogados del Centro de Derechos Humanos de la Montaña Tlachinollan y su incansable labor de defensa a las víctimas recurriendo a estrategias diversas para acceder a la justicia. $\mathrm{Al}$ acompañar a las mujeres en su proceso, las abogadas de Tlachinollan desnudan las prácticas, actitudes y percepciones que sistémicamente constituyen la discriminacion patriacal y racista del sistema de justicia y la ley.

Los TC resultan ser importantes espacios para visibilizar la impunidad en los procesos judiciales y muy especialmente para denunciar las graves violaciones a los derechos humanos cometidos contra mujeres 
indígenas, violaciones a su integridad como mujeres. En estos espacios simbólicos y altamente ritualizados la palabra de la víctima es la voz potente que expone los abusos del poder patriarcal e institucional y permite situar los contextos donde el drama humano cobran vida. En los TC el testimonio es el instrumento de los subalternos para narrar su versión de los hechos desde sus propias categorías y lenguajes; las descripciones encarnadas de la violencia física integran los sentimientos, los temores y los agravios sufridos aspectos que juegan en su reconocimiento como delitos de lesa humanidad, crímenes de odio o violencia sexual que viven como mujeres indígenas. Lo doloroso en estos casos es que suelen ser crímenes cometidos por los propios compañeros que ante momentos de rabia acumulada ejercen su fuerza física sobre las mujeres. Todos los hechos narrados dan cuenta de cómo las ideologías de género naturalizan la autoridad del hombre sobre la mujer despojándola de todo derecho o mecanismos para defender lo suyo.

Como lo sostiene Mora (2017b) para entender la injusticia que enfrentan las mujeres se requiere desmotar las construcciones hegemónicas y universalistas del derecho y poner atención a los significados sociales del daño. Los enfoques feministas legales -aunados a una perspectiva interseccional y cultural- permiten que emerjan las voces de las mujeres indígenas, desestabilizando las narrativas hegemónicas del daño y las violaciones a los derechos humanos, generalmente vistas desde una mirada masculina. El análisis feminista sensible a la cultura también interpela a los esencialismos comunitarios que tienden a construir miradas homogéneas de la vida local subordinando los intereses de las mujeres a la colectividad. En la medida que se privilegia la palabra de las mujeres violentadas sus voces revelan la supremacía masculina que las silencia en el proceso judicial y en las tramas comunitarias de la justicia.

Los tribunales de conciencia contribuyen a tener un mejor entendimiento de los silenciamientos que acallan la palabra de las mujeres violentadas. Con todo los TC involucran también formalismos $\mathrm{y}$ necesariamente la voz de las víctimas debe ajustarse a ciertos tiempos y ritmos que se imponen sobre las personas, con efectos simbólicos al hablar de temas tan profundos como lo es el dolor personal y colectivo (MACLEOD 2020). A pesar de la fuerza liberadora de los tribunales de conciencia, y a que impactan positivamente en la subjetividad y la agencia de las víctimas, difícilmente transforman desigualdades estructurales o cambios en el sistema que genera las injusticias. Tal vez lo más importante de los TC es el efecto simbólico 
que produce el llamado desesperado a la sociedad y al Estado para visibilizar que las violencias patriarcales que matan y someten a las mujeres indígenas.

¿Qué revelan los TC para el análisis de las violencias, la dimensión socio-cultural del daño y los sentidos de justicia a los que apelan las mujeres indígenas? Como lo apuntan varias autoras las violencias que enfrentan las mujeres no se restringen a la agresión físisca sino al conjunto de elementos que la provocan y posibilitan; y en ello juega el hecho que la palabra de la mujer suele valer menos que la del hombre (CROSBY y LYKES 2011; MORA, 2017b), lo que significa considerar el conjunto de violencias acumuladas que en el contexto de mujeres indígenas involucran elementos personales pero también de contexto social y comunitario.

De esta manera en todos los casos presentados por Tlachinollan en los TCs -ya sea los referidos a feminicidios, violación, violencia obstétrica y violencia institucionalla dimensión del agravio cobra mayor fuerza cuando se considera el conjunto de factores que hacen vulnerables a las mujeres y con base en los cuales suele ser revictimizada. Hacen ver también que por cada caso denunciado hay muchos otros que no se denuncian por el temor de las víctimas de ser sancionadas por sus esposos o familias $y$ prefieren mantener el silencio.
Lo que está en juego aquí es la dominación masculina montada y reforzada en entroques patriarcales comunitarios (PAREDES op cit) que remiten a las tramas racializadas y coloniales del poder con el efecto de silenciar a las mujeres indígenas. Es por ello que el testimonio como ejercicio de verdad es liberador en la medida que permite que las mujeres indígenas den su versión de los hechos desde sus propias epistemologías. El testimonio hace efecto en la audiencia gracias al apoyo de las abogadas que contextualizan y facilitan la traducción de los agravios en un lenguaje de derechos y en una secuencia comprensible de hechos. La lectura e intervención sensible y contundente de las juezas de conciencia -reconocidas por su trayectoria en favor de los derechos de las mujeres- consigue extender el reclamo al conjunto de la sociedad y ejercer presión sobre las autoridades judiciales estatales y locales. Para las mujeres violentadas acceder a la justicia significa tener las garantías de no ser amenazadas desde la precariedad de sus vidas; ya sea que se reconozca su derecho al patrimonio, se obligue a pagar una pensión, pero también que se penalice con cárcel al perpetrador; no se trata en este sentido de demandas en abstracto sino por el contrario, como- señala Brunneger y Falken (2016), de llevar la justicia al espacio propio y poner en relevancia los significados de la justicia en su dimensión cultural y contextual. 
Aunado al acompañamiento narrado y al montaje performativo de los TC, otro aporte importante del trabajo de defensoría de Tlachinollan es que hace ver que la justicia de género no es un nicho aparte desligado de otras problemáticas de la vida social. La violencia de género tiene claras conexiones con otras violencias y jerarquías de poder, a distintas escalas. La violencia de género -que se manifiesta en el despojo patrimonial, la agresión sexual y física, en el maltrato obstétrico, en la muerte violenta- es parte del mundo social ampliado y por lo mismo requiere ser atendida en su complejidad e interconectividad total. Las abogadas de Tlachinollan aportan al encuentro de distintas tradiciones de litigio y al análisis feminista mostrando que las jerarquías sexo/génericas no solo se circunscriben a lo doméstico-reproductivo sino también sino también constituyen la economía regional y nacional, dandole un sentido feminizado a la precarización neoliberal de la economía indígena (SPEED, 2016; ALTAMIRANO-JIMÉNEZ, 2013). Desde su trabajo comprometido las y los integrantes de Tlachinollan contribuyen a politizar la experiencia de violencia de género, tanto en el espacio comunitario como en la falta de atención de las instituciones del Estado, y lanzan un poderoso mensaje a la sociedad en general: que ninguna víctima se deja atrás, que todo agravio importa, y más si se trata de mujeres indígenas.

\section{Referências bibliográficas}

ALTAMIRANO-JIMÉNEZ, Isabel. Indigenous Encounters with Neoliberalism: Place, Women, and the Environment in Canada and Mexico. Vancouver: UBC Press. 2013.

BARTRA, Armando. Guerrero bronco. México: Ediciones ERA. 1996.

BRUNNEGGER, Sandra y FAULK, Karen Ann (eds). A Sense of Justice: Legal Knowledge and Lived Experience in Latin America. Stanford: Stanford University Press. 2016.

CANABAL, Beatríz y FLORES, Joaquín (2004). Montañeros. Actores sociaels en la Montaña de Guerrero, México, UAM-X

CROSBY, Alison \& LYKES, Brinton. "Mayan Women Survivors Speak: The Gendered Relations of Truth Telling in Postwar Guatemala" The International Journal of Transitional Justice, Vol. 5, pp 456-476. 2011

CONEVAL. Informe de Evaluación de la Política de Desarrollo Social 2018. Ciudad de México. 2018.

ESTRADA, Alba Teresa. "Crisis de inseguridad y guerra sucia en México", en Periódico El Sur, Martes 9 de sept.; pp: 2. 2014

ESTRADA, Alba Teresa. "Violencia política y derechos humanos. El papel de Tlachinollan en la movilización social y la construcción de alternativas en Guerrero, México", en Acta Académica, https://www.aacademica.org/000-062/1625. 2009.

FIGUEROA ROMERO, Dolores. "Políticas de Feminicidio en México: Perspectivas interseccionales de mujeres indígenas para reconsiderar su definición teórica-legal y las metodología de recolección de datos", 
Women's Movements and the Shape of Feminist Theory and Praxis in Latin America. Volume 20 Issue 8 Issue \#2 (of 2) 2019.

FIGUEROA ROMERO, Dolores y BARBEYTO, Arelly. "Strong Women: Memories of Miskitu Women forging Peace and Autonomy" En BARACCO, Luciano. Indigenous Struggles for Autonomy. The Caribbean Coast of Nicaragua. New YorkLondon: Lexington Books, Pp. 155-180, 2019.

FIGUEROA ROMERO, Dolores y SIERRA, María Teresa. "Alertas de género y mujeres indígenas: interpelando las políticas públicas desde los contextos comunitarios en Guerrero, México" en Canadian Journal of Latin American and Caribbean Studies, 45:1, pp 26-44, 2020.

FIGUEROA ROMERO, Dolores y SIERRA, María Teresa. "Los retos de la documentación (etnográfica) de las violencias hacia las mujeres indígenas y la disputa por la justicia de género en Guerrero" en Ichán Tecólotl. México: CIESAS, 2019.

GOBIERNO DEL ESTADO DE GUERRERO. Plan Estatal de Desarrollo 2015-2021. Guerrero. México. 2016.

HERNÁNDEZ CASTILLO, R. Aída. "Entre la justicia comunitaria y el litigio internacional. El caso de Inés Fernández ante la Corte Interamericana" en SIEDER, Rachel (ed.) Exigiendo justicia y seguridad. Mujeres indígenas y pluralidades legales en América Latina. México: CIESAS, 2017.

HERNÁNDEZ CASTILLO, R. Aída. Multiple InJustices: Indigenous Women, Law, and Political Struggle in Latin America. Tucson: The University of Arizona Press, 2016.

HERRERA AMAYA, Maria Elena. De Cochoapa a Villa de Arista, mano de obra para la agroindustria: racialización de la vulnerabilidad del jornalero agrícola. Tesis Doctoral en Antropología Social, México: CIESAS, 2018.

JARAMILLO SIERRA, Isabel C. "Latin American Feminist Legal Theory Taking Multiple Subordinations Seriously" en SIEDER, Rachel; ANSOLABEHERE, Karina, ALONSO, Tatiana (eds.) ROUTLEDGE HANDBOOK OF LAW AND SOCIETY IN LATIN AMERICA. New York: Routledge, p- 111-125, 2019.

THEIDON, Kymberley. Intimate Enemies: Violence and Reconciliation in Peru. Philadelphia: University of Pennsylvania Press, 2012.

LAGARDE, Marcela. "Antropología, Feminismo y Politica: Violencia Feminicida y Derechos Humanos de las Mujeres." En BULLEN, M. y Diez Mintegui, C. (eds.) Retos Teóricos y Nuevas Prácticas, Mexico: UNAM, p.p. 209-239, 2008.

LEMAITRE RIPOLL, Julieta. El derecho como conjuro. Fetichismo legal, violencia y movimientos sociales, Bogotá: Siglo del Hombre Editores. 2009.

LEY, MATTIACE Y TREJO. "Indigenous Resistance to Criminal Governance: Why Regional Ethnic Autonomy Institutions Protect Communities from Narco Rule in Mexico” LARR 54(1), pp 181-200, 2019.

MACLEOD, Morna. "Testimonios mayas durante el conflicto armado interno en Guatemala" en Desacatos, no 62, ene-abr, pp $36-53,2020$.

MACLEOD, Morna. "Ethical Tribunals. Maya Incursions into Symbolic Social Justice", 255-272, $2017 \mathrm{~b}$.

MOCIPOL (Monitor Civil de la Policía). Informe del Monitor Civil de la POlicía y de las Fuerzas de Seguridad en la Montaña de Guerrero, México: Fundar-IncideTlachinollan, 2011. 
MORA, Mariana. "Ayotzinapa and the Criminalization of Racialized Poverty in La Montaña, Guerrero, Mexico" PoLAR, vol. 40, no.1, pp-67-85, 2017.

MORA, Mariana. "Voces desde los silencios. Mujeres indígenas, seguridad y derechos frente a las violencias en la Montaña de Guerrero.” En SIEDER, Rachel (ed.) Exigiendo justicia y seguridad. Mujeres indígenas y pluralidades legales en América Latina. México: CIESAS, pp. 315-398, 2017b.

NICASIO, Maribel. Asambleas, urnas e inter politicidad en el nombramiento de autoridades en el municipio pluricultural de Tlapa de Comonfort, Montaña de Guerrero (1979-2005). Tesis Doctoral en Antropología Social. México: IIA-UNAM, 2017.

OVICOM. Informe de Homicidios Dolores de Mujeres del Estado de Guerrero (20052015). Chilpancingo: El Observatorio de Violencia Contra las Mujeres "Hannah Arendt", 2015.

PAREDES, Julieta. Hilando fino desde el feminismo comunitario. La Paz: Mujeres Creando, 2008.

ROSBERRY, William. "Hegemonía y el lenguaje de la controversia" En LAGOS, María y CALLA, Pamela (comps.) Antropología del Estado. Dominación y prácticas contestatarias en América Latina. 2007.

\section{SCHEPER-HUGHES, Nancy y}

BOURGOIS, Phillipe (eds). Violence in War and Peace. An Anthology. Hoboken, NJ: Blackwell Publishing, 2014.

SESNSP. Información sobre violencia contra las mujeres. México: Secretariado Ejecutivo del Sistema Nacional de Seguridad Pública. Corte enero-mayo. 2020.

SNIM. Ficha básica de información de población hablante de lengua indígena por municipio. México: Sistema Nacional de Información Municipal, 2010.

SPEED, Sharon. "States of Violence: Indigenous Women Migrants and Human Rights in the Era of Neoliberal Multicriminalism" Critique of Anthropology, 0(0) 1-22, 2016.

SIERRA, María Teresa. “Autonomías indígenas y justicia de género. Las mujeres de la policía comunitaria frente a la seguridad, la justicia y los derechos." En SIEDER, Rachel (ed.), Exigiendo justicia y seguridad. Mujeres indígenas y pluralidades legales en América Latina. México: México: CIESAS, pp- 161-204, 2017.

SIERRA, María Teresa. "Policías comunitarias y campos sociales minados en México. Construyendo seguridad en contextos de violencia extrema" Revista Abya Yala. Revista de Acceso a la Justicia y los Derechos en América Latina 2 (2): 325$351,2018$.

SIERRA FAJARDO, ANAID (en prensa)

"El silencio como castigo. Notas para discutir la eficacia simbólica del proceso penal oral a personas indígenas en Oaxaca”. Estudios socioculturales y politicos del derecho. En BLANCO, Mónica, GARZA, Jaqueline, JUÁREZ, Irene (coords.) A publicarse, Jalisco: El Colegio de Jalisco.

TLACHINOLLAN (Centro de Derechos Humanos de la Montaña). Manantial de la Resistencia y Torbellino de Esperanza. XXIV Informe de actividades (Julio 2017-Agosto 2018). Tlapa: Tlachinollan, 2018.

TLACHINOLLAN (Centro de Derechos Humanos de la Montaña) Mar de Luchas, Montaña de Ilusiones. XXIII Informe de actividades (Julio 2016- Agosto 2017). Tlapa: Tlachinollan, 2017.

DASS, Veena. Sujetos de dolor, agentes de dignidad. Bogotá: Universidad Nacional de Colombia, 2008. 